\title{
Factors affecting students' choice of educational administration major: Why do students join the program?
}

\author{
Didik Wardaya, Lantip Diat Prasojo, Sugiyono Sugiyono \\ Department of Educational Administration, Universitas Negeri Yogyakarta, Yogyakarta, Indonesia
}

\begin{tabular}{l} 
Article Info \\
\hline Article history: \\
Received Mar 15, 2021 \\
Revised Aug 4, 2021 \\
Accepted Sep 7, 2021 \\
\hline
\end{tabular}

\section{Keywords:}

Educational administration Factors

Major selection

SEM

Validation

\begin{abstract}
The study examined factors affecting Behavioral Intention (BI) regarding students' choice of educational administration as their major. Samples were taken from Indonesian students. The process was begun with the adaptation of survey instruments from previous studies validated through content validity. In testing the normality, Skewness and Kurtosis values were computed. Reliability assessment was applied through Cronbach's alpha. Exploratory Factor Analysis (EFA) and Confirmatory Factor Analysis (CFA) were both conducted for the constructs. In examining the relationship, Structural Equation Modeling (SEM) analysis using AMOS 23.0 was applied to 257 responses. The findings informed that two relationships were significant while the other two are insignificant. Perceived Behavioral Control (PBC) and Attitude (AT) significantly predicted BI, while Subjective Norm (SN) and Facilitating Condition (FC) did not significantly predict BI. The current study can expand an in-depth contribution and reference for further researchers as a basis of the empirical evidence in relation to the validated survey questionnaire. Access to the questionnaire may contribute to educational stakeholders establishing policies to improve students' interests in studying in an educational administration study program.
\end{abstract}

This is an open access article under the CC BY-SA license.

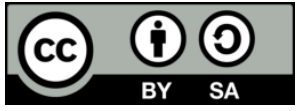

\section{Corresponding Author:}

Lantip Diat Prasojo

Department of Educational Administration

Universitas Negeri Yogyakarta

Kabupaten Sleman, Daerah Istimewa Yogyakarta 55281, Indonesia

Email: lantip@uny.ac.id

\section{INTRODUCTION}

The demand for education majors in Indonesia has consistently been high. In 2019, there are 5,998 educational study programs, with a total of approximately 1,480 million students or 250 thousand graduates each year [1]. Understanding student teachers' factors affecting their decision to become a teacher or an educational administrator by attending teacher education programs is essential since a necessary foundation to establish teacher education policies and plans is to increase the graduates' quality [2]-[4]. The elaboration of the factors affecting students' choice in a program is a decisive point to determine student recruitment policy in the future. It is also essential to manage the sustainability of teacher education programs and factors that derive a person from achieving something. A selection criterion of students' choice in choosing a program plays a significant role [4]-[6].

Students, including student teachers, tend to face the stressful major selection by limiting their selection). Sometimes, the selection process is complex because of inaccurate and limited information [7]. Studies about choosing educational majors have been widely available. Nevertheless, a few studies were conducted in developing countries like Indonesia. Even fewer of them elaborated on a validation process of a 
survey instrument establishment. Therefore, this study was conducted to examine the relationship among proposed constructs and to validate the survey questionnaire regarding Indonesian undergraduate students' choice of educational administration as their major of study. Two research problems emerged from the purposes: i) Is the proposed model valid and reliable for Indonesian context?; and ii) Are the proposed hypotheses significant? The paper would greatly contribute to the field of the study by providing a valid and reliable scale as well as an elaboration of relationship significances regarding the topic of the study.

After graduating from high schools, students tend to face stressful conditions to choose a college major, they tend to limit their criteria [2]. The process then became complicated due to short and incorrect information. Many models have been established to help students select their college major. The Campbell Interest and Skill Survey (CISS) shown informed a model for determining the selection of college major [8]. Lapan, Shaughnessy, and Boggs [9] addressed a factor analysis to measure major selection. The Analytic Hierarchy Process (AHP) was used to inform a tremendous predicting power for three factors: subject, other influence, and future careers [10]. In detail, students seemed to choose their major based on their perceived of some assessments, such as interest, compensation, image, reputation, and prestige. Expectations for supporting outputs and perceived task difficulty formed students' interest in choosing a college major. Interest is also reported to be predicted by subjects, self-confidence, and future careers [11].

Another factor is the salary in their future careers as a determinant of a college major. Students consider a significant belief that salary could support them in the future [12]. Previous studies informed that compensation plays a role in students' decision to choose a college major [10], [13]. This study focused on factors affecting undergraduate students' choice of educational administration as their major that was rarely elaborated by previous studies. In addition, the context of developing countries makes this study different from previous studies that have been conducted mainly in developed countries [2]-[4]. To make a strong theoretical concept, we adapted the Theory of Planned Behavior to achieve the purposes of the study [14].

In this study, we used Theory of Planned Behavior (TPB) [14], [15] that was developed to illustrate how people intend and decide to do certain behaviors by selecting outcomes with the best-expected value [16]. The theory involves three exogenous variables: Attitude (AT), Subjective Norm (SN), and Perceived Behavioral Control (PBC) to affect Behavioral Intention (BI) leading to actual behavior. Besides the three exogenous variables, this study extends the model by adding Facilitating Condition (FC) as one of the predictors Table 1 .

Table 1. Variable and definition

\begin{tabular}{cl}
\hline Variable & \multicolumn{1}{c}{ Definition } \\
\hline AT & In this study, AT is defined as students' perceived evaluation of the positivity or negativity of their choice of choosing \\
educational administration as their major of study.
\end{tabular}

The TPB framework has been widely applied in determining intentions and actions in various behavioral, technical, and medical science disciplines. In higher education, the framework has also been extensively used. For instance, PBC was reported to be the strongest predictor in predicting a student's intention to choose a business ethics course [17]. AT and SN were significant in predicting students' employment rate intention [18]. Regarding higher educational major selection, in addition, TPB was used to elaborate bachelor degree students for their major in higher education. In their study, the SN was reported to have a significant relationship with BI in choosing a major [19]. TPB use in choosing a business administration major was also reported [20]. SN and PBC path coefficients were significant in predicting BI, supporting two hypotheses of the study. Another research determined the reasons college undergraduates pursue a major in information technology [21]. The finding informed that those with high AT and PBC might be more likely to choose the major [21].

Further, reputation and image are also reported to influence AT for major college selection. For illustration, the social image also has an essential or critical role in a student's major selection. Career opportunities emerged to influence student AT and can be integrated as part of major evaluation, which is often described as job development [7], [21]. Other studies reflected SN or other people's influences like 
family and friends as a predictive role in predicting students' decisions regarding their college major [10], [21]. However, other scholars informed an insignificant relationship between SN and the major selection [17], [20]. Four relationships were proposed in this study concerning SN and BI; PBC and BI; AT and BI; FC and BI as shown in Figure 1. As a result, four hypotheses were established within this study:

H1: Students' SN will significantly influence BI regarding their educational administration choice as their major of study.

H2: Students' PBC will significantly influence BI regarding their educational administration choice as their major of study.

H3: Students' AT will significantly influence BI regarding their educational administration choice as their major of study.

H4: Students' FC will significantly influence BI regarding their educational administration choice as their major of study.

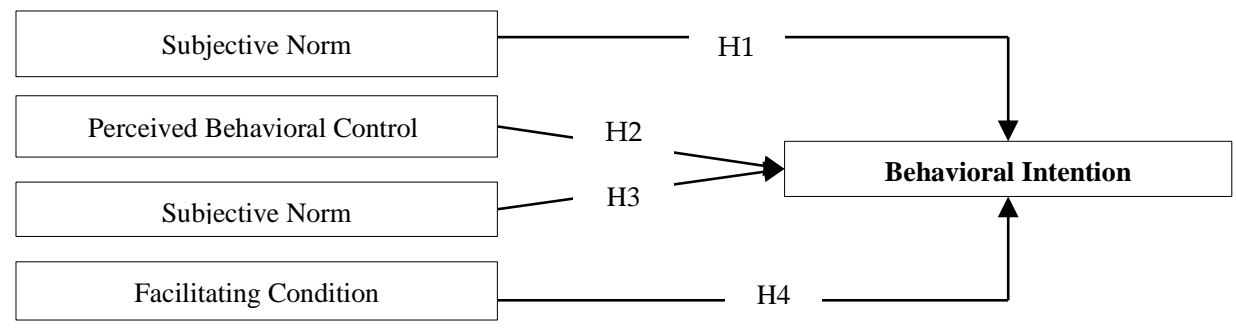

Figure 1. Proposed model

\section{RESEARCH METHOD}

\subsection{Participants and procedure}

The current study was conducted within a cross-sectional survey design [22]. A cross-sectional survey design is a quantitative method that facilitates the opportunity to administer a questionnaire to a group of sample or population of people to elaborate perceptions and characteristics of the sample or population [23], [24]. This study's population is all Indonesian undergraduate students of educational administration. Meanwhile, the sample of the study is 257 students whose major is educational administration; we used random cluster sampling in determining the sample of the study. The study respondents are undergraduate students from two state universities from two provinces, Jambi (University A) and Yogyakarta (University B). Female participants were 193 (75.1\%), and male participants were 64 (24.9\%). The gender disproportion in educational administration departments resulted in a more significant proportion of female respondents than male respondents. Regarding years they studied in university, first-year students were 78 respondents (3.4\%), second-year students were $74(28.8 \%)$, third-year students were $53(2.6 \%)$, fourth-year students were $48(18.7 \%)$, and fifth-year students were $4(1.6 \%)$. Available respondents voluntarily completed an onlinebased survey. They completed 29 items consisting of three items of demographic questionnaire and 26 items of main variable.

\subsection{Measures}

Three demographic items of the questionnaire addressed questions about university, gender, and years in university. Meanwhile, the main scale consisting of 26 indicators used in the current study was adapted from previous studies [14], [25], [26]. Researchers involved five experts in educational policy and administration in the beginning process of the survey development [27] as part of content validity. There were two focus group discussions held to evaluate the fitness of the survey instrument for Indonesian setting and context.

\subsection{Data analysis}

Data analysis in this study was begun with data screening. The data screening includes some considerations, namely handling missing data, multicollinearity, outliers, and normality. The computation was done through SPSS 23.0 program. A box plot for each construct recognized outliers. For the data normality of each construct, Skewness and Kurtosis were measured. The benchmark of the Skewness and Kurtosis values for each item should be in the range between -1.96 and +1.96 at a significance level of .050 [28], [29]. Multicollinearity was identified when the correlation matrix value refers to a value of more than .900 [30], [31]. Factor analysis was done to examine the validity of the survey instrument. Firstly, Exploratory Factor Analysis (EFA) was done for the factor structure of the model. Secondly, Confirmatory

Factors affecting students' choice of educational administration major: Why do students ... (Didik Wardaya) 
Factor Analysis (CFA) was undertaken to assess if the established dimensionality and factor-loading pattern can suit the Indonesian setting. EFA was computed through SPSS 23.0 to elaborate on the number of factors present within the dataset, report whether the factors are related, and elaborate on observed variables emerge to measure each factor.

The current study reported the Kaiser-Meyer-Olkin (KMO) value, Bartlett's value, factor loading, eigenvalue, and Varimax rotation within the CFA. The KMO index should be from 0 to 1 [27]. Loading values should be higher than .500 for factor analysis [28]; values over .800 were suggested as highly satisfactory. Bartlett's Test of Sphericity should be significant at $\mathrm{p}=<.050$. Loading value for each item should be equal to or above .500 . Besides, both the eigenvalue of the factors were also reported indicating the proportion of variance contribution extracted by each factor [28]. Factors with an eigenvalue $\geq 1.0$ were kept while $<1.0$ should be removed from the list of the factor. In this study, CFA was used to assess whether the developed dimensionality and loading pattern suits the Indonesian setting and context. The CFA criteria used in this study were the assessment of Chi-square $(\chi 2)$, Comparative Fit Index (CFI), Tucker Lewis Index (TLI), Root Mean-Square Error of Approximation (RMSEA). Besides, Cronbach's alpha coefficients, Composite Reliability (CR), and Average Variance Extracted (AVE) were computed to report the reliability of the survey instrument (both total and constructs) [32]. CFI should be >.900, TLI (>.900), RMSEA $(<.080)$, Cronbach's alpha coefficients $(>.700)$, CR $(>.700)$, and AVE $(>.500)$.

\section{RESULTS AND DISCUSSION}

The missing data calculated in this study ranged from 0 to $3 \%$ per indicator. Missing data were randomly found [33]. We dropped indicators with more than 5\% of missing data and retained those with $\leq 5 \%$. After completely filtering the missing data on all responses, we calculated means, standard deviations, correlation matrix, Skewness, and Kurtosis of the data as shown in Table 2. A preliminary analysis of all the items of AT, SN, PBC, FC, and BI achieved Univariate Normality; Skewness and Kurtosis values varied from -1.078 to 1.656 . Regarding Multicollinearity, inter-correlations among the five constructs are in the range of .521 to .809 . The outcome values indicate that the discriminant validity was satisfactory since the inter-correlation is below 900 .

Table 2. Means, standard deviations, correlation matrix, skewness and kurtosis

\begin{tabular}{cccccc}
\hline \multicolumn{1}{c}{ AT } & SN & PBC & FC & BI \\
\hline AT & 1 & $.809^{* *}$ & $.777^{* *}$ & $.762^{* *}$ & $.753^{* *}$ \\
SN & & 1 & $.712^{* *}$ & $.730^{* *}$ & $.647^{* *}$ \\
PBC & & & 1 & $.651^{* *}$ & $.781^{* *}$ \\
FC & & & & 1 & $.521^{* *}$ \\
BI & & & & & 1 \\
Skewness & -1.011 & -1.078 & -.776 & -.805 & -1.013 \\
Kurtosis & .991 & 1.656 & .220 & .514 & .911 \\
Mean & 5.9617 & 5.8911 & 6.0636 & 5.7442 & 6.1099 \\
SD & .76458 & .84421 & 73366 & .89430 & .74924 \\
\hline **Correlation is significant at the .01 level. & &
\end{tabular}

\subsection{Exploratory factor analysis}

Communalities, eigenvalues, and factor loading were informed in Table 3 of this manuscript, explaining the EFA process of the data analysis. The values of the communalities are regarded as the variance in each indicator computed pre and after the factor analysis. The values that were less than .500 should be dropped to fit for further analysis [28], [34]. Values of less than .500 show that less than half of the indicator's variance was defined to recognize the latent construct. From the computation, the communalities values were between .629 to .823 , exceeding .500 for a satisfactory explanation. Further, five factors with eigenvalues of more than 1.000 were computed through Varimax rotation, part of the factor analysis process. It explained $71.435 \%$ of the variance in total. After the Varimax, the component matrix was implemented in identifying items more related to each factor in the construct. Through the rotation, the current study informed 22 indicators items for measuring BI regarding Indonesian undergraduate students' choice of educational administration as their major of the study were registered by high loading values, from .534 to .808 or more significant than .500 . 
Table 3. EFA results

\begin{tabular}{|c|c|c|c|c|c|c|c|c|}
\hline \multirow{2}{*}{ Construct } & \multirow{2}{*}{ Item } & \multirow{2}{*}{ Communalities } & \multirow{2}{*}{ Eigen } & \multicolumn{5}{|c|}{ Factor } \\
\hline & & & & 1 & 2 & 3 & 4 & 5 \\
\hline \multirow[t]{6}{*}{ SN } & SN1 & .754 & 11.094 & .808 & & & & \\
\hline & SN3 & .823 & & .740 & & & & \\
\hline & SN2 & .713 & & .730 & & & & \\
\hline & SN4 & .825 & & .729 & & & & \\
\hline & SN5 & .789 & & .692 & & & & \\
\hline & SN6 & .693 & & .668 & & & & \\
\hline \multirow[t]{5}{*}{ PBC } & PBC1 & .756 & 1.899 & & .797 & & & \\
\hline & $\mathrm{PBC} 2$ & .715 & & & .746 & & & \\
\hline & PBC4 & .844 & & & .740 & & & \\
\hline & PBC3 & .815 & & & .668 & & & \\
\hline & PBC6 & .629 & & & .534 & & & \\
\hline \multirow[t]{4}{*}{ AT } & AT6 & .662 & 1.469 & & & .698 & & \\
\hline & AT1 & .722 & & & & .696 & & \\
\hline & AT4 & .809 & & & & .678 & & \\
\hline & AT2 & .645 & & & & & .447 & \\
\hline \multirow[t]{4}{*}{$\mathrm{FC}$} & $\mathrm{FC} 1$ & .823 & 1.095 & & & & .853 & \\
\hline & $\mathrm{FC} 2$ & .751 & & & & & .758 & \\
\hline & FC3 & .706 & & & & & .691 & \\
\hline & $\mathrm{FC} 4$ & .674 & & & & & .538 & \\
\hline \multirow[t]{3}{*}{ BI } & $\mathrm{BI} 3$ & .750 & 1.001 & & & & & .750 \\
\hline & $\mathrm{BI} 2$ & .789 & & & & & & .744 \\
\hline & BI1 & .780 & & & & & & .601 \\
\hline
\end{tabular}

\subsection{Confirmatory factor analysis}

Some indicators that loadings are below .500 were deleted in the CFA computation. After the process, the CFA results through SPSS AMOS 23.0 program are adequate. The factor structure reached satisfactory model fit for the Indonesian context, for measuring BI regarding Indonesian undergraduate students' choice of educational administration as their major, $\chi 2=154.500, \chi 2 / \mathrm{df}=1.644$, RMSEA $=.067$, $\mathrm{TLI}=.945$ and $\mathrm{CFI}=.957$. As a result, the CFA model indicates the appropriate structure of the proposed model. All factor loadings of the CFA model varied from .700 to .900; the values exceeded the threshold of .500 [28], [34]. It performs adequate convergent validity. Moreover, correlations among the five constructs ranged from .470 to .810 , exhibiting good discriminant validity. The finalized model emerged as the baseline for the subsequent analyses regarding cross-validation (Table 4).

\subsection{Reliability of the scales}

Reliability is defined as the consistency of the scores obtained in data analysis [22]. It means that scores should always be consistent when academics address the instrument at various times. In this study, the degree of reliability through the computation of Cronbach's alpha, Composite Reliability (CR), and Average Variance Extracted (AVE) were computed. The Cronbach's alpha $(\alpha)$ values of all constructs are acceptable, ranging above .700; SN obtained the highest value with .892 while the lowest value emerged on AT $(\alpha=.811)$. All CR values exceed .600, indicating high internal consistency; the highest CR value (.843) was obtained by PBC; the lowest one was the BI (.701). The appropriate AVE values indicate that the current dataset obtained satisfactory acceptable discriminant validity. Table 4 informs the values of loading, CR, AVE, and Cronbach's alpha.

Table 4. CFA and reliability of the scale

\begin{tabular}{ccccccc}
\hline Criterion & Results & Construct & Item (loading) & CR & AVE & $\alpha$ \\
\hline Chi-square $\left(\chi^{2}\right)$ & 154.500 & SN & SN1 (.810), SN2 (.820), SN3 (.800), SN5 (.860) & .893 & .823 & .892 \\
$\chi 2 /$ df & 1.644 & PBC & PBC1 (.760), PBC4 (.900), PBC6 (.710) & .835 & .790 & .827 \\
CFI & .957 & AT & AT1 (.750), AT4 (.890), AT6 (.810) & .858 & .816 & .811 \\
TLI & .945 & FC & FC1 (.840), FC2 (.870), FC3 (.700) & .847 & .803 & .837 \\
& & BI & BI1 (.850), BI2 (.780), BI3 (.850) & .866 & .826 & .868 \\
\hline
\end{tabular}

\subsection{Testing the hypothetical structural model}

From the structural model examination through SEM analysis using AMOS 23.0, two relationships were significant as shown in Figure 2. Meanwhile, the other two relationships are not significantly correlated. Hypothesis 1 was confirmed because significant relationships emerged between $\mathrm{SN}$ and $\mathrm{BI}(\beta=.305, \mathrm{t}=.2 .564$, $p<.05)$. Similarly, Hypothesis 2 was also positively confirmed; PBC is positively related to BI $(\beta=.857$, $\mathrm{t}=6.169, p<.05)$ regarding Indonesian undergraduate students' choice of educational administration as their 
major. Similarly, AT was also significantly correlated to BI $(\beta=-.118, \mathrm{t}=-.1449, p=.147)$. In contrast, last relationship between FC and BI was found to be not significantly related $(\beta=.025, \mathrm{t}=-.1449, p=.769)$.

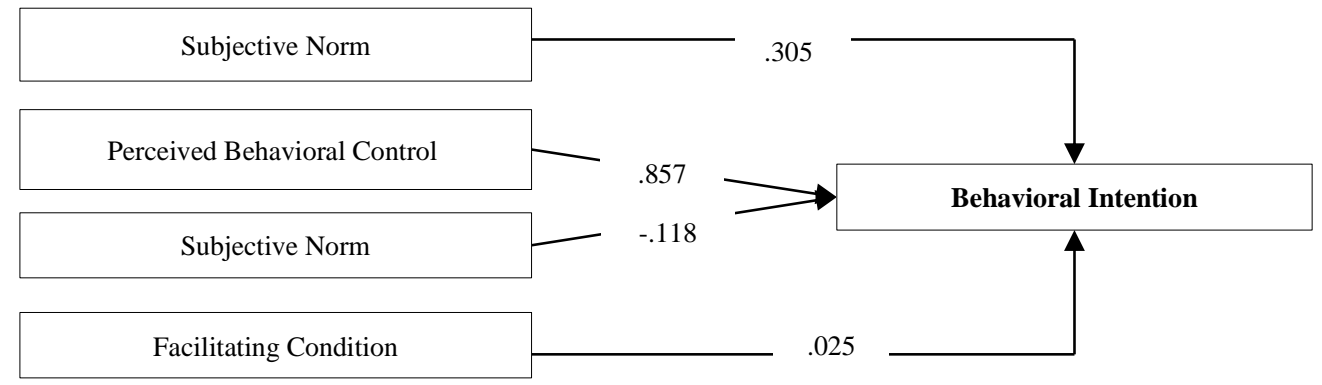

Figure 2. Structural model

\subsection{Discussion}

The academic findings of the current study herein are noteworthy due to the limited research in recognizing the behavioral factors of students' intention to choose an educational administration major for their study in higher institutions. As a result, the valid and reliable scale proposed in this study produces a strong baseline providing solutions to the natural research problems based on the hypothesis elaboration and evaluation [35], [36]. The current study's findings indicate that SN (H1) influences students' intentions to major in educational administration. This result supports the role of other people as a predicting factor in students' intention to choose the educational administration major. The result agrees prior findings where BI was related to the SN [20], [37], [38]. As an influence on selecting a major, SN might emerge prior to the attendance date of college meetings [37]. The undergraduate student candidates tend to heavily be exposed by media and other conventional influences, such as parents, siblings, and friends [39], [40]. Maloni, et al. [41] reported that the influences of professors and high school teachers as the key role in predicting student's choice of a major were significant. Therefore, encouraging seminars and conferences to promote a major should always be conducted, inviting experts and professionals in educational administration, such as school owners, principals, and education professors.

Regarding $\mathrm{H} 2$, the relationship between $\mathrm{PBC}$ and $\mathrm{BI}$ was also significant. The finding confirms past studies where PBC is reported to be an immediate predecessor to BI [20], [42], [43]. Informed the nonsignificance of the AT to BI, PBC seems to fill the gap as a substantial predictor. Its path coefficient of .744 and $p$-value of <.001 were instrumental in achieving a fit model of the study. It represents the beliefs of the students regarding their expectations of a successful journey to attend educational administration. In the future, they can be useful educational administration staff. Their experiences might influence PBC; it might engage the results with the major content. Terms like capability, ability, and control referred to in the questionnaire indicators facilitate a measurement regarding participants' beliefs concerning their major selection of educational administration.

The hypothesis (H3) regarding the expected correlation between AT and BI was not facilitated. Among TPB's main variable, AT has been reported as an important element influencing BI [41]. Despite the significant results, some researchers reported that AT and BI had no significant relationship [38], [44], [45]. The result could be triggered by a lack of information and knowledge about the current educational administration condition. Opportunities for their career in educational administration areas might still be unclear for some of the students. Therefore, no correlation was detected in this relationship. Critical thinking could also be a factor that weakens the relationship between AT and BI in choosing a major in higher education institutions. As a result, they might depend on the perspectives of their personal, social experiences. In addition to the three main variables of TPB reported in this study, FC was also hypothesized to predict BI regarding Indonesian undergraduate students' choice of educational administration as their major of study. The findings reported that it was not significantly correlated with BI. Similarly, FC was also not significant in predicting BI [46], [47]. Supporting facilities such as availability of sports fields, proper environment, supporting buildings, and easy access for technology in education would not influence Indonesian educational administration students' choice of the major. 


\section{CONCLUSION}

Major selection challenges can cause long-term benefits or losses for students to have; it is related to their career path. Their decision should be based on sufficient information and knowledge. It should not be a trivial decision. The study's findings informed that $\mathrm{SN}$ and $\mathrm{PBC}$ had significant roles in predicting $\mathrm{BI}$ of the students choosing educational administration as their major. This study's findings facilitate considerable insight and urgency for university providers in addressing the diverse challenges to influence students' decisions to major in educational administration. Universities in Indonesia should convince students by providing students with factors equally rooted in the SN and PBC as part of TPB antecedents toward BI. Otherwise, they may fail to lead the students for a promising lifelong career effectively.

Future studies with more participants are suggested to conduct. An in-depth analysis through a qualitative approach is needed to get a more understanding of personal student experience regarding major selection in a higher education institution. The valid and reliable resulted from this study can be adapted and addressed with a great contribution to the literature review. Educational stakeholders intend to issue policies to improve students' interests in studying in an educational administration study program may use the findings of the current study as a guide.

\section{REFERENCE}

[1] Pangkalan Data Pendidikan Tinggi (PDDikti), "Graph of the number of study programs," (in Indonesian), 2021. [Online]. Available: https://pddikti.kemdikbud.go.id/prodi.

[2] R. Baker, E. Bettinger, B. Jacob, and I. Marinescu, "The Effect of Labor Market Information on Community College Students' Major Choice,” Econ. Educ. Rev., vol. 65, pp. 18-30, Aug. 2018.

[3] L. A. Phelps, E. M. Camburn, and S. Min, "Choosing stem college majors: Exploring the role of pre-college engineering courses," J. Pre-College Eng. Educ. Res., vol. 8, no. 1, pp. 1-24, 2018, doi: 10.7771/2157-9288.1146.

[4] S. A. Barbera, S. D. Berkshire, C. B. Boronat, and M. H. Kennedy, "Review of Undergraduate Student Retention and Graduation Since 2010: Patterns, Predictions, and Recommendations for 2020," J. Coll. Student Retent. Res. Theory Pract., vol. 22, no. 2, pp. 227-250, 2020.

[5] P. A. Denice, "Choosing and Changing Course: Postsecondary Students and the Process of Selecting a Major Field of Study," Sociol. Perspect., vol. 64, no. 1, pp. 82-108, 2021.

[6] S. Avargil, Z. Kohen, and Y. J. Dori, "Trends and perceptions of choosing chemistry as a major and a career," Chem. Educ. Res. Pract., vol. 21, no. 2, pp. 668-684, 2020, doi: 10.1039/C9RP00158A.

[7] C. Cobb-Walgren and B. Pilling, "Does Marketing Need Better Marketing? A Creative Approach to Understanding Student Perceptions of the Marketing Major," e-Journal Bus. Educ. Scholarsh. Teach., vol. 11, no. 1, pp. 97-117, 2017.

[8] D. P. Campbell, "The Campbell Interest and Skill Survey (CISS): A Product of Ninety Years of Psychometric Evolution," J. Career Assess., vol. 3, no. 4, pp. 391-410, 1995.

[9] R. T. Lapan, P. Shaughnessy, and K. Boggs, "Efficacy expectations and vocational interests as mediators between sex and choice of math/science college majors: A longitudinal study," J. Vocat. Behav., vol. 49, no. 3, pp. 277-291, 1996.

[10] S. E. Strasser, C. Ozgur, and D. L. Schroeder, "Selecting a Business College Major: An Analysis of Criteria and Choice Using the Analytical Hierarchy Process," Am. J. Bus., vol. 17, no. 2, pp. 47-56, 2002.

[11] O. Umarji, P. McPartlan, and J. Eccles, "Patterns of math and English self-concepts as motivation for college major selection," Contemp. Educ. Psychol., vol. 53, pp. 146-158, Apr. 2018.

[12] E. B. Puertas and T. Y. Rivera, "Factors that influence career choice in primary care among medical students starting social service in Honduras," Rev. Panam. Salud Publica/Pan Am. J. Public Heal., vol. 40, no. 5, pp. 309$317,2016$.

[13] Y. Shi, "The Determinants of College Graduates' Migration Decision and Its Impact on Starting Salaries in China," Ph.D. Dissertation, Columbia University 2015, doi: 10.7916/D8X9294S.

[14] I. Ajzen, "The theory of planned behavior," Organ. Behav. Hum. Decis. Process., vol. 50, no. 2, pp. 179-211, 1991.

[15] W. Edwards, "The theory of decision making," Psychol. Bull., vol. 51, no. 4, pp. 380-417, 1954.

[16] J. Van Der Pligt and N. K. De Vries, "Expectancy-value models of health behaviour: The role of salience and anticipated affect," Psychol. Heal., vol. 13, no. 2, pp. 289-305, 1998.

[17] P. Y. Cheng and M. C. Chu, "Behavioral Factors Affecting Students' Intentions to Enroll in Business Ethics Courses: A Comparison of the Theory of Planned Behavior and Social Cognitive Theory Using Self-Identity as a Moderator," J. Bus. Ethics, vol. 124, no. 1, pp. 35-46, 2014.

[18] J. T. Huang, "Application of planned behavior theory to account for college students' occupational intentions in contingent employment," Career Dev. Q., vol. 59, no. 5, pp. 455-466, 2011.

[19] L. M. Tan and F. Laswad, "Students' beliefs, attitudes and intentions to major in accounting," Account. Educ., vol. 15 , no. 2 , pp. $167-187,2006$.

[20] M. S. Hiatt, J. A. Swaim, and M. J. Maloni, "Choosing an undergraduate major in business administration: Student evaluative criteria, behavioral influences, and instructional modalities," Int. J. Manag. Educ., vol. 16, no. 3, pp. 524-540, 2018. 
[21] W. Zhang, "Why IS: Understanding Undergraduate Students' Intentions to Choose an Information Systems Major," J. Inf. Syst. Educ., vol. 18, no. 4, pp. 447-458, 2007.

[22] J. W. Creswell, Educational research: Planning, conducting, and evaluating quantitative and qualitative research, 5th ed. Pearson, 2015.

[23] J. R. Fraenkel and N. E. Wallen, "The Basic of Educational Research," in How to design and evaluate resaerch in education with PowerWeb. New York, McGraw-Hill, 2012.

[24] L. D. Prasojo, et al., "An Asian Perspective: The dataset for validation of Teachers' Information and Communication Technology Access (TICTA)," Data Br., vol. 30, no. 1, Jun. 2020, doi: 10.1016/j.dib.2020.105592.

[25] V. Venkatesh, M. G. Morris, G. B. Davis, and F. D. Davis, "User acceptance of information technology: Toward a unified view," MIS Q. Manag. Inf. Syst., vol. 27, no. 3, pp. 425-478, 2003.

[26] V. Venkatesh, S. A. Brown, L. M. Maruping, and H. Bala, "Predicting different conceptualizations of system USE: The competing roles of behavioral intention, facilitating conditions, and behavioral expectation," MIS Q. Manag. Inf. Syst., vol. 32, no. 3, pp. 483-502, 2008.

[27] A. Habibi, F. D. Yusop, and R. A. Razak, "The role of TPACK in affecting pre-service language teachers' ICT integration during teaching practices: Indonesian context," Educ. Inf. Technol., vol. 25, no. 3, pp. 1929-1949, Nov. 2020.

[28] Z. Awang, A handbook on SEM: Structural Equation Modelling. Universiti Teknologi MARA Press, 2011

[29] L. D. Prasojo, et al., "Teachers' burnout: A SEM analysis in an Asian context," Heliyon, vol. 6, no. 1, p. e03144, 2020, doi: 10.1016/j.heliyon.2019.e03144.

[30] J. Pallant, SPSS survival manual, 3rd ed. McGrath Hill, 2005.

[31] Z. Awang, Structural Equation Modeling using AMOS graphic. Universiti Teknologi MARA Press, 2012.

[32] S. Ghavifekr, "Factors affecting use of e-learning platform (SPeCTRUM) among University students in Malaysia," Educ. Inf. Technol., vol. 22, no. 1, pp. 75-100, 2017.

[33] R. B. Kline, Principles and practice of structural equation modelling, 4th ed. Guilford Press, 2015.

[34] J. Hair, W. Black, B. Babin, and R. Anderson, Multivariate Data Analysis: A Global Perspective. Pearson Education, 2010.

[35] L. D. Prasojo, W. Wijayanti, L. Yuliana, N. Agus, A. Habibi, and M. F. M. Yaakob, "Instruments' validation of access to motivation, skills, and use of digital technology: EFL context in indonesia," Stud. English Lang. Educ., vol. 7, no. 2, pp. 308-322, 2020.

[36] A. Habibi, F. D. Yusop, and R. A. Razak, "The dataset for validation of factors affecting pre-service teachers' use of ICT during teaching practices: Indonesian context," Data Br., vol. 28, Feb. 2020, doi: 10.1016/j.dib.2019.104875.

[37] J. T. Barnowe, P. J. Frost, and M. Jamal, "When personality meets situation: Exploring influences on choice of business major," J. Occup. Psychol., vol. 52, no. 3, pp. 167-176, 1979.

[38] K. K. Byon, S. Lee, and T. A. Baker, "A cross-cultural study of purchase intention of sponsored products based on American and Korean spectators of the 2010 FIFA World Cup South Africa," Sport. Bus. Manag. An Int. J., vol. 4, no. 2, pp. 158-177, 2014.

[39] J. L. Hurst and L. K. Good, "Generation Y and career choice: The impact of retail career perceptions, expectations and entitlement perceptions," Career Dev. Int., vol. 14, no. 6, pp. 570-593, 2009.

[40] J. Luscombe, I. Lewis, and H. C. Biggs, "Essential elements for recruitment and retention: Generation Y," Educ. Train., vol. 55, no. 3, pp. 272-290, 2013

[41] M. J. Maloni, C. R. Scherrer, S. M. Campbell, and E. Boyd, "Attracting students to the field of logistics, part 1," Transportation Journal, vol. 55, no. 4. pp. 420-442, 2016.

[42] C. J. Armitage and M. Conner, "Efficacy of the theory of planned behaviour: A meta-analytic review," Br. J. Soc. Psychol., vol. 40, no. 4, pp. 471-499, 2001.

[43] M. Conner and P. Sparks, "Theory of Planned Behaviour and Health Behaviour," in Predicting health behaviour: Research and practice with social cognition models, 2nd ed. Open University Press, 2005, pp. 170-222.

[44] S. N. Bhuian, D. A. Amyx, and H. M. Shamma, "An extension of consumer environmental behavior research among expatriates," Int. J. Commer. Manag., vol. 24, no. 1, pp. 63-84, 2014.

[45] S. B. ferraz, C. buhamra, M. laroche, and A. R. veloso, "Green Products: a Cross-Cultural Study of Attitude, Intention and Purchase Behavior," RAM. Rev. Adm. Mackenzie, vol. 18, no. 5, pp. 12-38, 2017.

[46] S. A. Nikou and A. A. Economides, "Factors that influence behavioral intention to use mobile-based assessment: A STEM teachers' perspective," Br. J. Educ. Technol., vol. 50, no. 2, pp. 587-600, 2019.

[47] T. Teo, G. Sang, B. Mei, and C. K. W. Hoi, "Investigating pre-service teachers' acceptance of Web 2.0 technologies in their future teaching: a Chinese perspective," Interact. Learn. Environ., vol. 27, no. 4, pp. 530-546, 2019. 